\title{
Canadian Thoracic Society Pulmonary Standards Committee
}

\author{
Allan L Coates MD FRCPC
}

In the current issue of the Canadian Respiratory Journal, Tan et al (1) (pages 321-326) propose new reference equations for Caucasian adults. This publication is timely, and points to the need for the development of 'Made in Canada' prediction equations for lung function.

In 2010, the Canadian Thoracic Society (CTS) Executive struck a new committee, with the goal of aiding and improving the use of lung function measurements in Canada. The committee first met at the Canadian Respiratory Conference held in in Halifax (Nova Scotia) in 2010, and then again for a full day meeting in Montreal (Quebec) that fall. During discussion, it became apparent that there are very significant regional differences in the running of pulmonary function laboratories. Some provinces have rigorous accreditation standards, while others are much more lax. Some of the standards have essentially been adopted from those in other countries, while some have a more 'Canadian' approach. One of the first tasks of the committee was to attempt to develop recommendations for pulmonary function testing that would be applicable in an accreditation situation, and would be a resource to those running pulmonary function laboratories. The principles driving these recommendations would be to comply with international standards, largely those set in joint documents by the American Thoracic Society and the European Thoracic Society (2-5), but also to have as much Canadian content as possible.

With regard to laboratory accreditation, it is clear that some provinces have a detailed and elaborate approach, whereas others are extremely superficial, focusing on issues such as correct patient identification or whether tanks of compressed gas are appropriately secured to the walls. While the CTS had no interest or mandate to become an accrediting body, it is believed that CTS-endorsed guidelines would greatly aid accrediting bodies in reviewing pulmonary function laboratories and, hopefully, would act as a reference document for quality assurance in the laboratories. Presently, the committee is reviewing accreditation at home and abroad, and is planning to create an amalgam of recommendations that are consistent with world standards but are also practical in the Canadian setting. This setting includes large university teaching hospitals with complete pulmonary function laboratories as well as much smaller laboratories outside the academic centres. In fact, many of these smaller laboratories are in small centres far removed from university influence, and it is often these laboratories that are most in need and most eager for information to improve the value of the testing that they perform.

Members of the committee are also working with Statistics Canada in relation to the recent and ongoing Canadian Health Measures Survey to develop Canadian reference values for spirometry. The committee has also approached Statistics Canada, and urged that the next survey include the measurement of carbon monoxide diffusing capacity to generate Canadian reference equations that are based on the current population and using modern equipment. The other pressing need that has been identified is the lack of reference values for Aboriginal populations. The committee is exploring approaches to population testing that would shed light on the apparent differences between the widely accepted reference values for Caucasians - usually Hankinson et al (6) - or the more recent reiteration that includes children as young as six years of age (7) and the diverse Aboriginal populations in the country.

The article by Tan et al (1) goes some way toward a 'Made in Canada' solution, but has some advantages and disadvantages. It does provide a lower limit of normal, and the difference between the data from Hankinson et al (6), the largest North American survey to date, is miniscule. Because it is an adults-only data set, it is able to use a much simpler approach to the reference equations, which may make applicability much easier than the approach by Stanojevic et al (7).

The primary disadvantage will be the issues of continuity between the reference equations for adults and children, problems which are avoided by both Stanojevic et al (7) and Hankinson et al (6). Similar to the data set of Stanojevic et al (7), it uses data from more than one survey, obtained with different equipment and separated by more than 10 years. Hopefully, all of these issues will be addressed when the new Statistics Canada data set becomes available.

While the committee has a wide geographical representation and includes pediatrics, it is also eager to hear suggestions and comments from other CTS members with regard to the projects mentioned above, as well as other areas that members believe the committee should focus its attention on.

\section{REFERENCES}

1. Tan WC, Bourbeau J, Hernandez P, et al; for the COLD study investigators; and for the LCHE study investigators. Canadian prediction equations of spirometric lung function for Caucasian adults 20 to 90 years of age: Results from the Canadian Obstructive Lung Disease (COLD) study and the Lung Health Canadian Environment (LHCE) study. Can Respir J 2011;18:321-6.

2. Miller MR, Hankinson JL, Brusasco V, et al. Standarisation of spirometry. Eur Respir J 2005;26:319-38.

3. MacIntyre NR, Crapo RO, Viegi G, et al. Standardisation of the single-breath determination of carbon monoxide uptake in the lung. Eur Respir J 2005;26:720-35.

4. Wanger JK, Clausen JL, Coates AL, et al. Standarisation of the measurement of lung volume. Eur Respir J 2005;26:511-22.

5. Miller MR, Crapo RO, Hankinson JL, et al. ATS/ERS Task Force. General considerations for lung function testing. Eur Respir J 2005;26:153-61.

6. Hankinson JL, Odencrantz JR, Fedan KB. Spirometric reference values from a sample of the general U.S. population. Am J Respir Crit Care Med 1999;159:179-87.

7. Stanojevic S, Wade A, Stocks J, et al. Reference ranges for spirometry across all ages: A new approach. Am J Respir Crit Care Med 2008; 177:253-60.

\footnotetext{
Correspondence: Dr Allan L Coates, Division of Respiratory Medicine, The Hospital for Sick Children, University of Toronto; Chair, CTS Pulmonary Function Standards Committee, clo Janet Sutherland, Director, Canadian Thoracic Society, 300-1750 Courtwood Crescent, Ottawa, Ontario K2C 2B5. Telephone 613-569-6411, fax 613-569-8860, e-mail jsutherland@lung.ca
} 


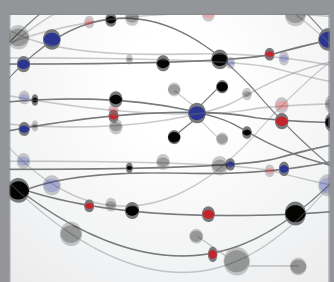

The Scientific World Journal
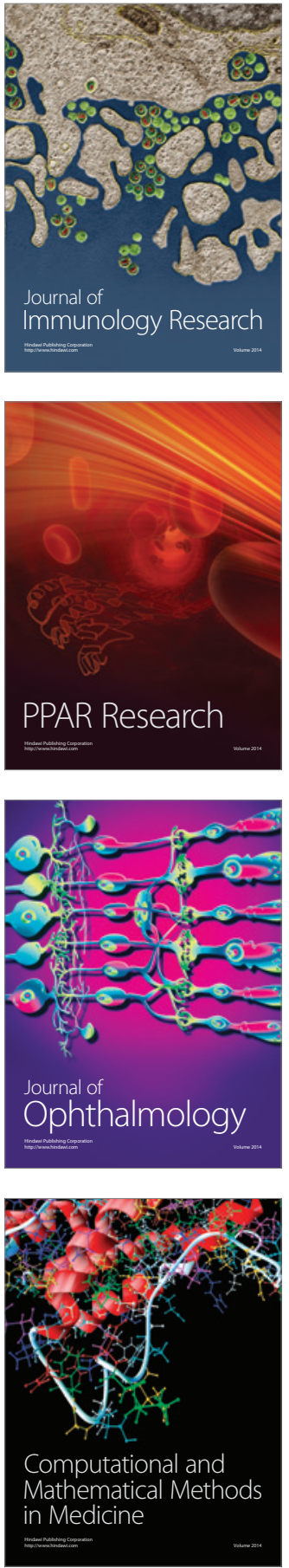

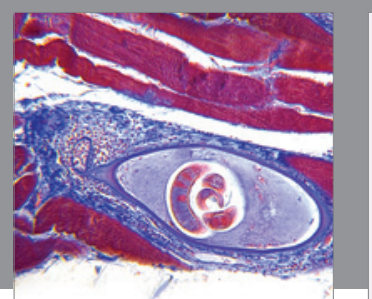

Gastroenterology Research and Practice

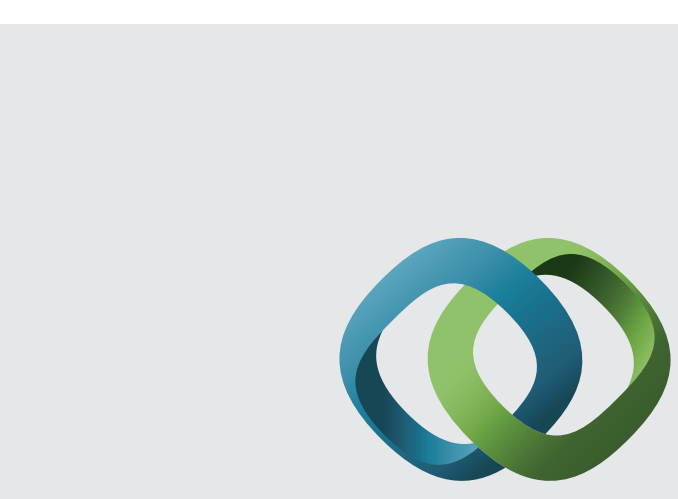

\section{Hindawi}

Submit your manuscripts at

http://www.hindawi.com
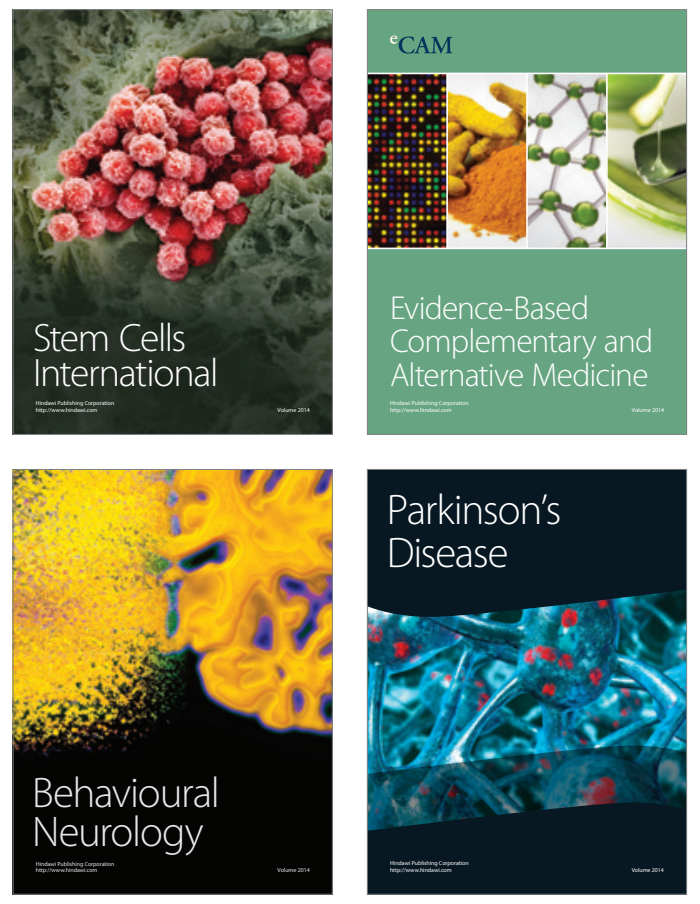
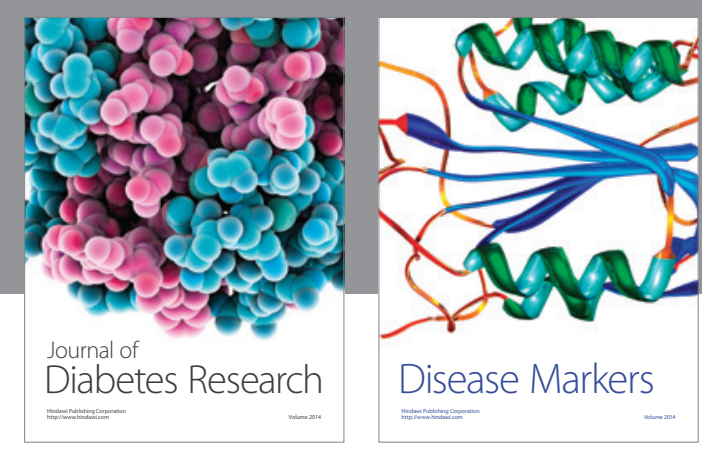

Disease Markers
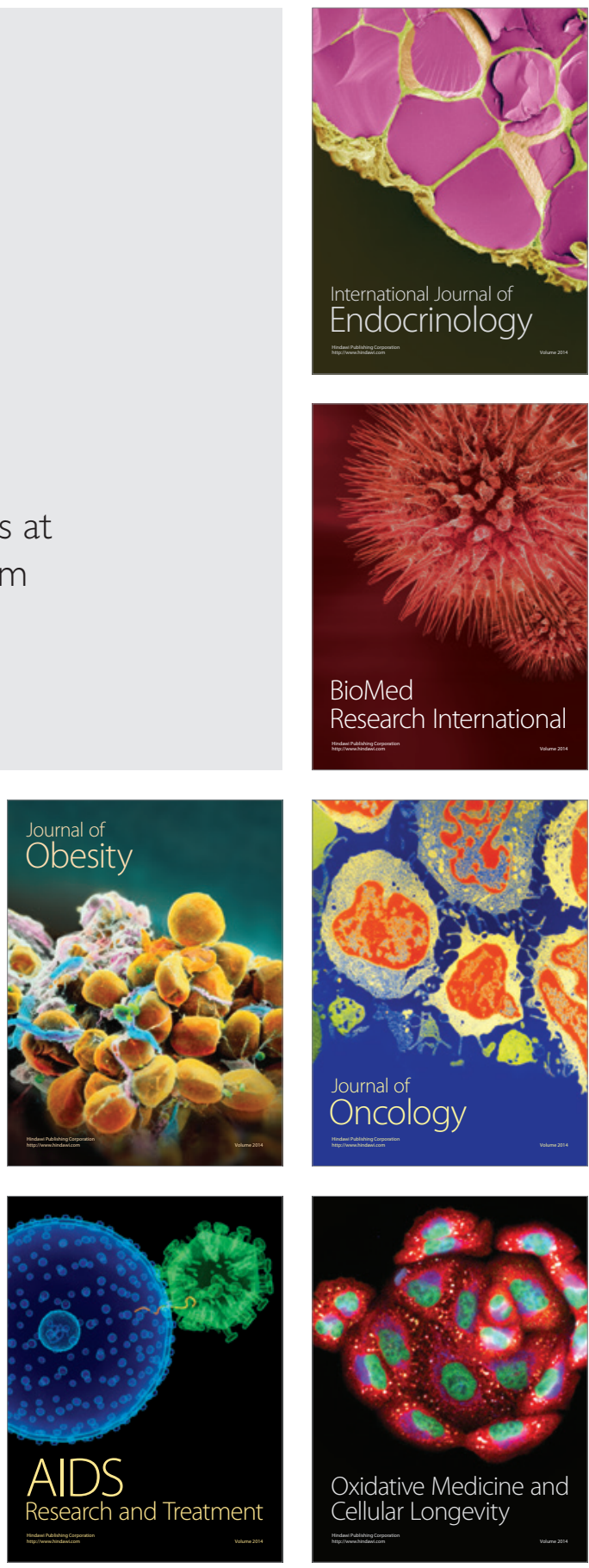